\title{
Positive and Negative Emotion Regulation in College Athletes: A Preliminary Exploration of Daily Savoring, Acceptance, and Cognitive Reappraisal
}

\author{
James D. Doorley ${ }^{1} \cdot$ Todd B. Kashdan $^{1}$ \\ Accepted: 31 December 2020 / Published online: 22 January 2021 \\ (๑) The Author(s), under exclusive licence to Springer Science+Business Media, LLC part of Springer Nature 2021
}

\begin{abstract}
Background Despite increasing interest in positive psychological states, we know little about how regulatory responses to positive (savoring) compared to negative events (e.g. acceptance, cognitive reappraisal) influence emotional functioning. Savoring may be particularly helpful for athletes who are often trained to attend more to negative (e.g. rectifying weaknesses) compared to positive stimuli (e.g. enjoying progress).

Methods Sixty-seven college athletes completed a two-week daily diary study. Using multi-level modeling, we first explored whether various regulatory responses to daily negative events predicted unique variance in daily emotions (i.e. happy, content, grateful, sad, angry, annoyed). Next, we tested whether savoring positive events strengthened the association between event intensity and positive daily emotions. Finally, we tested whether regulatory responses to positive compared to negative events had stronger moderating (buffering) effects on the association between daily negative event intensity and daily emotions.

Results Based on 836 daily observations, reappraising and accepting negative events were the only strategies that predicted unique variance in daily emotions. Savoring enhanced positive emotions related to positive events. Reappraising negative events buffered associations between negative event intensity and decreased daily gratitude, while savoring positive events buffered associations between negative event intensity and increased anger, annoyance, and average negative emotions. Accepting negative events had similar effects.

Conclusions Savoring positive events may be an underappreciated strategy for helping athletes regulate emotions related to negative events. Since our sample predominantly identified as white and female, further research is needed to understand savoring use and effectiveness among the full, diverse spectrum of college athletes.
\end{abstract}

Keywords Emotion regulation $\cdot$ Acceptance $\cdot$ Cognitive reappraisal $\cdot$ Savoring $\cdot$ Athletes

College athletes face challenges beyond those of typical undergraduates in the United States (Kimball and Freysinger 2003). These include rigorous training and competitive schedules with minimal days off, frequent travel, external pressures to perform, difficulties with coaches and teammates, athletic and academic role conflict, and insufficient time to nurture non-sport relationships and activities (Broughton and Neyer 2001; Cosh and Tully 2015; Loudon et al. 2013; Settles et al. 2002; Watson and Kissinger 2007). Effectively regulating emotions that arise from daily

James D. Doorley

jdoorley@gmu.edu

1 Department of Psychology, George Mason University, MS 3F5, 4400 University Dr, Fairfax, VA 22030, USA stressors is crucial for optimal functioning (e.g. Min et al. 2013; Troy and Mauss 2011; Tugade and Fredrickson 2007). However, an overreliance on global trait measures of emotion regulation (e.g. Gross and John 2003; Uphill et al. 2012) and a predominant focus on sport-specific situations (e.g. Gaudreau and Blondin 2004a, b; Martinent et al. 2015; Poczwardowski and Conroy 2002) gives an incomplete picture of the regulatory strategies and stressors college athletes encounter in sport and life.

Numerous studies have explored strategies for regulating negative emotions, such as cognitive reappraisal (i.e. changing one's thinking about a situation; e.g. Gross and John 2003; McRae et al. 2012), acceptance (i.e. mindfully acknowledging distressing emotions or situations without struggling to change them; e.g. Gratz and Tull 2010; Wolgast et al., 2011), problem-solving (e.g. Bell and D'Zurilla 2009), 
social support seeking (e.g. Marroquín 2011), and cognitive and behavioral avoidance (i.e., trying not to think or act in ways that exacerbate distress; Kashdan et al. 2006; Olatunji et al. 2010). Evidence suggests that certain strategies, such as cognitive reappraisal and acceptance, are associated with healthier emotional functioning, while strategies involving suppression or avoidance of distress are associated with emotional dysfunction (e.g. Brockman et al. 2017; Hofmann et al. 2009; Kuba and Scheibe 2017; Machell et al. 2015; Moore et al. 2008). Experience-sampling methods, such as smartphone-based daily diary and ecological momentary assessment (EMA), have been used to uncover the temporal dynamics, contextual correlates, and consequences of these regulatory strategies in the daily lives of healthy adults and clinical populations (e.g. Benson et al. 2019; Colombo et al. 2020; Gruber et al. 2013; Ludwig et al. 2020; Visser et al. 2018). Research suggests experience sampling methods mitigate recall bias when assessing momentary psychological states, including emotions (e.g. Ellison et al. 2020; Scollon et al. 2009).

More intensive experience sampling methods (e.g. EMA) have been used successfully to study athletes' self-talk during sport performance (e.g. Dickens et al. 2018; Van Raalte et al. 2019), but no studies to our knowledge have tested the feasibility of EMA for studying emotion regulation in college athletes' daily lives during their competitive seasons. Given college athletes' demanding schedules, daily diary methods (i.e. recalling and reporting on daily experiences at the end of each day) have been more frequently used to capture college athletes' psychological experiences in daily life (e.g. Riley et al. 2020; Shapiro et al. 2017; Shorey et al. 2014; Tamminen et al. 2019). Daily diaries demonstrate considerable yet imperfect agreement with real-time EMA measures when assessing daily emotions, with specific bias toward recalling stronger/more salient emotional experiences when thinking about the day as a whole (Neubauer et al. 2019). However, this bias makes daily diaries suitable for capturing particularly strong emotional experiences in daily life - both positive and negative - and associated emotion regulation strategies.

Only recently have researchers begun to explore the regulation of positive emotions related to daily positive events. Cross-sectional and longitudinal data suggest that savoring, a set of cognitive-behavioral strategies to upregulate positive emotions related to positive events (e.g. counting blessings, sharing with others, deeply processing sensory details), enhances positive emotions (e.g. Bryant and Veroff 2007; Jose et al. 2012; Silton et al. 2020; Sytine et al. 2019; Quoidbach et al., 2015). Consistent with savoring theory (e.g. Bryant and Veroff 2007), evidence from daily diary studies suggest that savoring moderates (strengthens) associations between positive events and momentary positive emotions (Jose et al. 2012). Interestingly, diary data also suggest that savoring moderates (buffers) the negative association between daily hassles and daily hope, optimism, and self-efficacy (Sytine et al. 2019), suggesting that savoring may promote healthy responses to daily stressors. Similarly, brief 1-2 week savoring interventions have been shown to downregulate negative emotions and enhance resilience (defined as the ability to bounce back from stressful experiences; Smith et al. 2008), at post-intervention (Hurley and Kwon 2013; McMakin et al. 2011) and three months later (Smith and Hanni 2019). With grueling schedules comprised of more "journeys" (training and practice) than "arrivals" (winning games or tournaments, individual accolades, etc.), savoring smaller daily achievements and positive events may be an overlooked strategy for enhancing college athletes' emotional functioning in the face of daily stressors.

Despite an abundance of research on regulatory responses to negative emotions and experiences, there is still much to learn about effective emotion regulation strategies for college athletes in daily life. Given the culture of college sports in the United States, which prizes relentless efforts to improve, ameliorate deficiencies, and learn from defeat, athletes may benefit from noticing and savoring daily positive experiences, such as incremental sport improvement or time spent with teammates. Savoring is associated with increased positive emotions and healthy responses to daily negative events, suggesting savoring may be at least as effective as other frequently studied regulatory strategies focused solely on negative events/emotions (e.g., cognitive reappraisal, acceptance). To our knowledge, only two experience sampling studies of savoring exist (Jose et al. 2012; Sytine et al. 2019) and none have focused on athletes or compared the effects of savoring to other regulatory strategies on daily emotions. Using daily diary assessments over a two-week span during athletes' competitive seasons, we tested the following hypotheses:

1. Controlling for negative event intensity, daily emotion regulation strategies will be associated with the quality of daily emotional experiences. Specifically, greater use of cognitive reappraisal, acceptance, problem-solving, and social support in response to daily negative events will be associated with more daily happiness, contentment, and gratitude and less sadness, anger, and annoyance. Greater use of cognitive and behavioral avoidance in response to daily negative events will be associated with the opposite (i.e., less daily happiness, contentment, and gratitude and more sadness, anger, and annoyance).

2. Consistent with existing theory (Bryant and Veroff 2007) and research (Jose et al. 2012), savoring daily positive events will moderate associations between positive event intensity and the quality of daily emotions such that greater savoring will strengthen the positive association 
between positive event intensity and positive emotions and strengthen the negative association between positive event intensity and negative emotions.

3. Similar to the most effective regulatory strategies from Hypothesis 1, savoring positive events will moderate (buffer) associations between greater daily negative event intensity and (1) less positive emotion and (2) more negative emotions at the daily level.

\section{Method}

\section{Participants and Procedures}

Participants were 67 collegiate athletes from George Mason University (GMU; $n=53$ ) and Catholic University of America (CUA; $n=14)$. Due to the COVID-19 pandemic, collegiate sports were suspended during the Spring 2020 season. Thus, we were forced to un-enroll an additional 30 Spring sport athletes who signed consent. Our final sample of athletes represented various sports, including women's soccer, women's volleyball, men's and women's swimming and diving, men's and women's basketball, men's and women's cross country and track and field, women's lacrosse, and softball. Recruitment procedures differed slightly between universities. At GMU, team coaches were contacted via email and given general study information. If coaches expressed interest, a member of the research staff scheduled a meeting with their teams to explain our study, train athletes on the daily diary software (PACO Personal Analytics Companion; Evans 2017), and obtain informed consent. At CUA, athletes were recruited directly via flyers and mass emails. Athletes were eligible to participate if they spoke and read English and owned a smartphone with a reliable internet connection. The average age of the final sample was 19.85 $(S D=1.25)$. Participants were $89 \%$ women; $91.1 \%$ White, 3.5\% Hispanic/Latino, 2.4\% Asian/Pacific Islander, and 2.9\% Other.

Athletes who provided written consent to participate were re-contacted via email and invited to complete baseline questionnaires and demographics (as part of a larger study on college athlete resilience) followed by a daily diary assessment via PACO (Personal Analytics Companion; Evans 2017). Athletes from different teams completed the daily diary portion of the study at different times during their respective seasons, which were specified by coaches (at GMU) or the athletes themselves (at CUA) based on the number and importance of practices and competitions. Participants were pinged daily at 7:00 PM for 14 consecutive days to complete short, 5-10 min surveys about their day, which included questions about their most positive and negative events that day, positive and negative emotions, and regulatory responses to their most positive and negative events.
Participants were instructed to complete surveys after finishing all sport-related activities and before 3:00 AM the following day. Participants were compensated with up to $\$ 40$ in Amazon eGift cards for their participation ( $\$ 10$ for baseline assessment, up to $\$ 30$ for completing all daily diaries). All procedures were approved by both universities' IRBs.

\section{Measures}

\section{Positive and Negative Emotions}

Daily positive and negative emotions were measured using select emotion adjectives from the Positive and Negative Affect Schedule-Extended Form (PANAS-X; Watson and Clark 1999) using the stem, "How much does this word describe your mood today?" Responses were on a 5-point Likert scale from $(1=$ "Very slightly or not at all," $2=$ "A little," 3 = "Moderately," 4= "Quite a bit," 5= "Extremely"). Original emotion items from the PANAS-X included, Cheerful, Joyful, Content, Sad, and Angry. We added two additional items for this study: Grateful and Annoyed. We used only seven emotion items for greater simplicity and lower participant burden while capturing emotions across the valance and arousal dimensions (e.g., Joyful = high valence/high arousal, Content $=$ high valence/low arousal, Angry $=$ low Valance/high arousal, $\mathrm{Sad}=$ low valence/low arousal; see Gerber et al. 2008). Since Joyful and Cheerful were highly correlated at the between- $(r=0.95)$ and withinperson level $(r=0.70)$, we combined to form a composite variable, Happy. The resulting three positive emotion adjectives were averaged to create the positive emotions scale $\left(R_{C}=0.84\right)$, and the three negative emotion adjectives were averaged to create the negative emotions scale $\left(R_{C}=0.77\right)$. To explore the impact of regulatory strategies on specific positive and negative emotions, we entered individual emotion items/adjectives as outcomes in analyses for Hypotheses 2 and 3 .

\section{Positive and Negative Events}

Participants reported on their most positive event that day with the following item: "Please describe today's most positive event. Be as specific as you can." They rated the intensity of their most positive events ("How positive was this event?") on a 5-point Likert scale ( $1=$ "Not at all," $2=$ "A little," 3 = "Moderately," 4 = "Quite a bit," $5=$ "Extremely"). Participants also reported on their most negative event that day ("Please describe today's most negative event. Be as specific as you can."). Consistent with the primary and secondary appraisal model of coping (Lazarus 2006; Lazarus and Folkman 1984), participants then provided an appraisal of the intensity of their most negative 
event each day ("How negative was this event?") using the same 5-point Likert scale.

\section{Ways of Savoring Checklist (WOSC; Bryant and Veroff 2007)}

Participants rated the extent they savored their most positive daily events using four WOSC items with the highest factor loadings from Jose et al. (2012). Items were rated on a 5-point Likert Scale (1 = "Not at all," $2=$ "A little," $3=$ "Moderately," $4=$ "Quite a bit," 5= "Extremely"). Items included, "I talked to another person about how good I felt," "I looked for other people to share it with," "I thought about what a lucky person I am that so many good things have happened to me," and "I thought about sharing the memory of this later with other people." Savoring items were averaged together to create a total savoring score $\left(R_{C}=0.75\right)$.

\section{Emotion Regulation Strategies}

Participants rated the extent that they used various emotion regulation strategies in response to daily negative events using items from Aldridge-Gerry and colleagues' daily coping scale. Items were rated on a 4-point Likert scale ( $1=$ "Not at all," 2 = "A little," $3=$ "A medium amount," $4=$ "A lot"). The factor structure of this scale was validated in an undergraduate sample (Roesch et al. 2010). Items from this scale were drawn from other published coping measures with valid total scores in college student and older adolescent samples, including the Brief COPE (Carver 1997; Carver et al. 1989) and the Responses to Stress Questionnaire (Connor-Smith et al. 2000). For the present study, we focused on frequently researched regulatory strategies that we believed would be associated with SC, including, Social Support Seeking $\left(R_{C}=0.75\right)$ - comprised of Emotion-Focused (two items; e.g., "I talked to my family about how I was feeling") and Problem-Focused Support $\left(R_{C}=0.82\right)$ (two items; e.g., "I figured out what I could do by talking to my friends"), Cognitive Reappraisal $\left(R_{C}=0.78\right)$ ( 2 items; originally called "positive cognitive restructuring," e.g., "I reminded myself that things could be worse"), Acceptance $\left(R_{C}=0.32\right)$ (two items; e.g., "I learned to live with it"), Problem-Solving $\left(R_{C}=0.82\right)$ - comprised of Direct Problem-Solving ( 2 items; e.g., "I did something to solve the problem") and Cognitive Decision-Making (2 items; e.g., "I thought about what I need to know to solve the problem"), Behavioral Avoidance $\left(R_{C}=0.51\right)$ (two items; originally called "avoidant actions," e.g., "I tried to stay away from the problem"), and Cognitive Avoidance $\left(R_{C}=0.43\right)$ (two items; e.g., I tried to put it out of my mind). Research suggests that this measure, and the scales from which it is adapted, predict daily alcohol consumption (Aldridge-Gerry et al. 2011), trait levels of fear (Ollendick et al. 2001), heart-rate reactivity to stress and internalizing/externalizing symptoms (Connor-Smith et al. 2000), and changes in the symptom severity of psychological disorders (e.g., Meyer 2001). Subscale reliabilities will be further discussed in the results section.

\section{Data Analytic Strategy}

To evaluate the interdependence of observations, we examined the intraclass correlations (ICCs) for each outcome (daily happiness, gratitude, contentment, sadness, anger, and annoyance). Results showed a substantial proportion of variance was attributable to differences between people (ICC range $=0.23-0.48$; Table 1). As such, hypotheses were tested using two-level models with daily observations (level 1) nested within people (level 2), though no level 2 variables were used as predictors or outcomes in analyses. All predictors were within-person mean-centered so that scores represented deviations from each athlete's mean during the 2-week daily assessment period. In addition to unstandardized coefficients $(b)$, we reported standardized coefficients $(\beta)$ as a measure of effect size, which is a recommended approach in multi-level modeling (e.g. Lorah 2018).

The reliability of daily multi-item scales was calculated in SPSS based on G Theory (e.g. Brennan 1992; Shrout and Lane 2012) using code specified by Bolger and Laurenceau (2013). This approach is optimal for repeated daily measures in multi-level models and allowed us to account for multiple sources of variance, including differences between people, items, and time (i.e., days). Specifically, our index of reliability (" $R_{C}$ ") assessed the extent to which within-person changes were reliable across days. $R_{C}$ is higher when variance is predominantly attributable to differences across people and time rather than differences across items and error.

Primary analyses were performed using the lme 4 package (Bates et al. 2007) in R 3.6.1 (R Core Team, 2019). In order to reduce limitations related to our smaller sample size at the between-person level, our analyses focused exclusively on within-person predictions to harness all 836 daily diary responses across participants. To test the effects of daily emotion regulation strategies (in response to negative events) on daily emotions (Hypothesis 1), we entered each strategy - cognitive reappraisal, acceptance, problem-solving, social support seeking, cognitive avoidance, and behavioral avoidance - as predictors of daily positive and negative emotions in separate models. Next, we included significant predictors from these models together to test which strategies predicted unique variance in daily positive and negative emotions, again, controlling for negative event intensity. Since the intensity of daily negative events was correlated with daily positive $(r=-0.31)$ and negative emotions $(r=0.45)$ at the withinperson level (Table 1), we entered negative event intensity as a covariate in all models for Hypothesis 1. 
Table 1 Between- and within-person correlations and descriptive statistics

\begin{tabular}{|c|c|c|c|c|c|c|c|c|c|c|c|}
\hline & 1 & 2 & 3 & 4 & 5 & 6 & 7 & 8 & 9 & 10 & 11 \\
\hline \multicolumn{12}{|l|}{ Daily Measures } \\
\hline 1. Negative Event Intensity & - & $.15^{*}$ & .02 & $-.09 *$ & $.33^{*}$ & $.39 *$ & $.13^{*}$ & $-.10^{*}$ & $-.14 *$ & $-.31 *$ & $.45^{*}$ \\
\hline 2. Problem-Solving & $.30 *$ & - & $.20^{*}$ & .02 & $.14^{*}$ & $.12^{*}$ & $.07 *$ & .02 & .06 & .05 & .03 \\
\hline 3. Cognitive Reappraisal & .06 & $.57 *$ & - & $.28^{*}$ & $.09 *$ & $.15^{*}$ & $.14^{*}$ & $.12 *$ & $.11^{*}$ & $.19^{*}$ & -.06 \\
\hline 4. Acceptance & .11 & $.46^{*}$ & $.36^{*}$ & - & .01 & .07 & .04 & $.08^{*}$ & $.08^{*}$ & $.12^{*}$ & $-.12^{*}$ \\
\hline 5. Social Support & $.44^{*}$ & $.50 *$ & $.46^{*}$ & $.39 *$ & - & $.25^{*}$ & $.17 *$ & -.03 & .07 & $-.14^{*}$ & $.33 *$ \\
\hline 6. Cognitive Avoidance & $.51^{*}$ & $.53 *$ & $.51^{*}$ & $.58^{*}$ & $.58^{*}$ & - & $.39 *$ & $.07 *$ & .00 & $-.17 *$ & $.29^{*}$ \\
\hline 7. Behavioral Avoidance & $.29 *$ & $.54^{*}$ & $.59 *$ & $.37 *$ & $.67 *$ & $.69 *$ & - & .01 & .03 & $-.07 *$ & $.19 *$ \\
\hline 8. Positive Event Intensity & $.35^{*}$ & $.41^{*}$ & $.33^{*}$ & .24 & .22 & .23 & .23 & - & $.44^{*}$ & $.30^{*}$ & $-.17 *$ \\
\hline 9. Savoring Positive Event & .09 & $.57^{*}$ & $.71^{*}$ & $.34 *$ & $.55^{*}$ & $.45^{*}$ & .55 & $.55^{*}$ & - & $.33^{*}$ & $-.16^{*}$ \\
\hline 10. Positive Emotions & -.18 & $.37 *$ & $.53^{*}$ & .13 & .16 & .04 & .25 & $.55^{*}$ & $.65^{*}$ & - & $-.49 *$ \\
\hline 11. Negative Emotions & $.57 *$ & .06 & -.08 & -.04 & $.33^{*}$ & $.43^{*}$ & .19 & -.11 & -.04 & $-.35^{*}$ & - \\
\hline \multicolumn{12}{|l|}{ Descriptives } \\
\hline Scale & $1-5$ & $1-4$ & $1-4$ & $1-4$ & $1-4$ & $1-4$ & $1-4$ & $1-5$ & $1-5$ & $1-5$ & $1-5$ \\
\hline M & 3.07 & 2.31 & 2.06 & 2.68 & 1.56 & 2.35 & 1.66 & 4.03 & 2.17 & 3.00 & 1.82 \\
\hline SD & 1.16 & .87 & .90 & 1.00 & .65 & .87 & .76 & .93 & .85 & 1.02 & .98 \\
\hline ICC & .30 & .30 & .47 & .27 & .23 & .33 & .38 & .27 & .41 & .48 & .37 \\
\hline
\end{tabular}

Notes. ${ }^{*} p<.05$

Coefficients below the diagonal represent between-person correlations Coefficients above the diagonal represent within-person correlations Scale $=$ the scale on which each variable is scored. $I C C=$ Intraclass correlation

To test the effects of positive event intensity, savoring positive events, and their interaction on daily emotions (Hypothesis 2), we entered these variables as predictors of daily positive and negative emotions. Since the intensity of daily positive events was correlated with positive $(r=0.33)$ and negative emotions $(r=-0.16)$ at the within-person level, we entered positive event intensity as a covariate in all models for Hypothesis 2. To test the emotionally protective effects of emotion regulation strategies related to both negative and positive events (Hypothesis 3), we selected the regulatory strategies that predicted (more) positive and/or (less) negative daily emotions from Hypothesis 1. In one set of models, we entered negative event intensity as a predictor of daily emotions moderated by the most effective regulatory strategies from Hypothesis 1. In another set of models, we entered negative event intensity as a predictor of daily emotions moderated by the extent participants savored their most positive events (with positive event intensity as a covariate). For Hypotheses 2 and 3, we entered individual positive (happy, grateful, content) and negative emotions (sad, angry, annoyed) along with average levels of each as outcomes.

\section{Results}

\section{Descriptive Statistics}

Between- and within-person correlations and descriptive statistics for primary study variables are presented in Table 1. Participants who completed fewer than 7 daily diaries in total were excluded from analyses $(N=8)$. The remaining participants $(N=67)$ completed an average of 12.89 daily diaries $(S D=2.19)$ for a total of 836 daily observations. Due to forced response settings on the PACO app, completed daily diaries had no missing data. Participants were instructed to delete the PACO app and discontinue their completion of daily diaries after 14 days. However, several participants completed more than the 14 required daily diaries. In these cases, up to two diary entries past the $14^{\text {th }}$ day were accepted, and any additional diary entries were removed from analyses. Daily diary compliance was not significantly correlated with daily positive and negative emotions at the within-person level and was thus not accounted for during analyses.

The reliability of primary daily measures was generally high except for the two-item acceptance scale $\left(R_{C}=0.32\right)$. When examining the items comprising this scale, it is 
understandable that participants may have responded differently to, "I learned to live with it" versus, "I just accepted the fact that this is the way it is." While this scale was designed for daily use (e.g. Aldridge-Gerry et al. 2011), "learning to live with it" may be less applicable to daily stressors (which are often transient and do not require long-term recalibration of expectations) and thus, may have decreased internal consistency. Still, our acceptance measure arguably captures two different features of acceptance, broadening content validity compared to a single-item measure. It is no surprise that reliability was lower on average for 2-item daily scales (except for cognitive reappraisal; $R_{C}=0.78$ ) compared to measures with three or four items (e.g. positive and negative emotions, savoring). As a caveat, appropriate methods for calculating the reliability of daily measures in multilevel models are poorly understood, and when done correctly, reliability may be lower than when using conventional methods (e.g., cronbach's alpha) as if observations were independent (i.e. not nested) (Nezlek 2011, 2012).

\section{Hypothesis Testing}

Hypothesis 1: Daily regulatory strategies related to negative events predicting daily emotions.
Multilevel regression results (Table 2) revealed that, controlling for negative event intensity, greater use of daily problem solving predicted more daily positive emotions. Greater use of daily cognitive reappraisal and acceptance were associated with more positive and less negative emotions, also controlling for negative event intensity. Contrary to hypotheses, greater use of daily social support was not associated with daily positive emotions and was associated with more negative emotions. As hypothesized, greater use of cognitive avoidance and behavioral avoidance were associated with more daily negative emotions but were not associated with positive emotions. When combining regulatory strategies that predicted more positive and less negative daily emotions in the same models (Table 3), cognitive reappraisal was the only regulatory strategy that predicted more daily positive emotions while acceptance was the only regulatory strategy that predicted less daily negative emotions (controlling for negative event intensity in both models).

Hypothesis 2: Positive event intensity predicting daily emotions, moderated by savoring.

Positive event intensity predicted more positive and less negative emotions. Daily savoring predicted more positive emotions and less sadness, annoyance, and average negative emotions controlling for positive event intensity. There were also significant interaction effects between daily positive
Table 2 Multilevel regression results with regulatory strategies predicting same day emotions, controlling for the intensity of negativity events

\begin{tabular}{|c|c|c|c|c|c|c|}
\hline \multirow{2}{*}{$\begin{array}{l}\text { Outcomes: } \\
\text { Predictors: }\end{array}$} & \multicolumn{3}{|c|}{ Positive emotions } & \multicolumn{3}{|c|}{ Negative emotions } \\
\hline & $b$ & $\beta$ & $t$ & $b$ & $\beta$ & $t$ \\
\hline Problem-solving & $.09 *$ & $.06^{*}$ & 2.72 & -.04 & -.03 & -1.14 \\
\hline Cognitive reappraisal & $.22 *$ & $.14 *$ & 5.85 & $-.08 *$ & $-.05 *$ & -2.08 \\
\hline Acceptance & $.08 *$ & $.06 *$ & 2.84 & $-.08 *$ & $-.07 *$ & -2.65 \\
\hline Social support & -.06 & -.03 & -1.25 & $.27 *$ & $.15^{*}$ & 6.04 \\
\hline Behavioral avoidance & -.04 & -.02 & -.96 & $.17 *$ & $.10^{*}$ & 4.14 \\
\hline Cognitive avoidance & -.06 & -.04 & -1.25 & $.27 *$ & $.19^{*}$ & 6.04 \\
\hline
\end{tabular}

Notes. $* p<.05$

Regulatory strategies predicting better emotional outcomes (more positive or less negative emotions) are bolded

\begin{tabular}{|c|c|c|c|c|c|c|}
\hline \multirow{2}{*}{$\begin{array}{l}\text { Outcomes: } \\
\text { Predictors: }\end{array}$} & \multicolumn{3}{|c|}{ Positive Emotions } & \multicolumn{3}{|c|}{ Negative Emotions } \\
\hline & $b$ & $\beta$ & $t$ & $b$ & $\beta$ & $t$ \\
\hline Negative event intensity & $-.24 *$ & $-.21 *$ & -9.42 & $.35^{*}$ & $.33 *$ & 13.75 \\
\hline Problem-solving & .06 & .04 & 1.70 & N/A & N/A & N/A \\
\hline Cognitive reappraisal & $.19 *$ & $.12 *$ & 4.83 & -.05 & -.03 & -1.39 \\
\hline Acceptance & .04 & .03 & 1.34 & $-.06^{*}$ & $-.05 *$ & -2.15 \\
\hline
\end{tabular}

Notes. ${ }^{*} p<.05$. Cognitive reappraisal and acceptance were entered into the same models predicting positive and negative emotions. N/A = Problem-Solving did not predict negative emotions in Table 2, so it was not included 


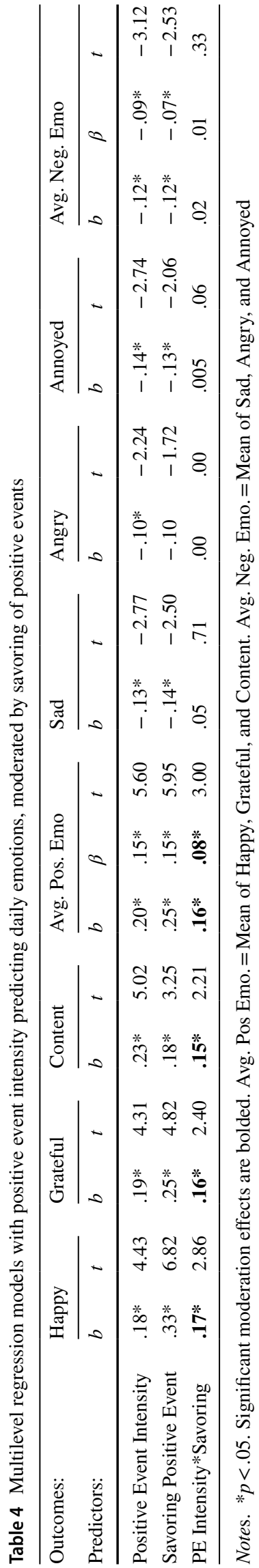

event intensity and savoring predicting daily happiness, gratitude, contentment, such that greater positive event intensity was more strongly associated with positive emotions when athletes savored these events more (Table 4, Fig. 1).

Hypothesis 3: Negative event intensity predicting daily emotions, moderated by cognitive reappraisal, acceptance, and savoring

In models containing cognitive reappraisal, there were main effects for negative event intensity predicting less positive emotion and cognitive reappraisal predicting more positive emotions. Negative event intensity and cognitive reappraisal interacted to predict gratitude such that greater daily cognitive reappraisal buffered the negative association between negative event intensity and gratitude. The negative event intensity $\mathrm{x}$ cognitive reappraisal interaction did not predict any other positive or negative emotions (Table 5, Fig. 2).

In models containing acceptance, there were main effects for negative event intensity and acceptance predicting less negative emotion. Negative event intensity and acceptance interacted to predict less sadness, anger, and average negative emotions (but not annoyance) such that greater daily acceptance buffered positive associations between negative event intensity and sadness, anger, and average negative emotions (Table 6, Fig. 3).

In models containing savoring, there were main effects for positive event intensity predicting more negative and less positive emotion, negative event intensity predicting less positive and greater negative emotion, and savoring predicting more positive emotion but not less negative emotion. Negative event intensity and savoring interacted to predict daily anger, annoyance, and average negative emotions (but not sadness) such that greater savoring buffered positive associations between negative event intensity and anger, annoyance, and average negative emotions. Negative event intensity and savoring did not interact to predict positive emotions (Table 6, Fig. 4).

\section{Discussion}

Using a two-week experience sampling approach, we found that, controlling for the intensity of negative events, greater daily use of cognitive reappraisal and acceptance in response to these events predicted more positive and less negative emotion while problem solving predicted only more positive emotion. Cognitive avoidance, behavioral avoidance, and interestingly, social support seeking each predicted more daily negative emotion and did not predict positive emotions after controlling for the intensity of negative events. 


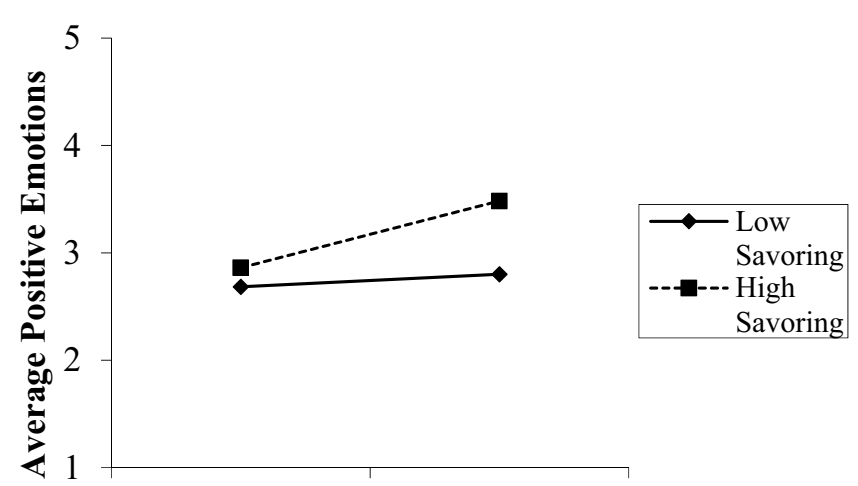

Low PE Intensity High PE Intensity

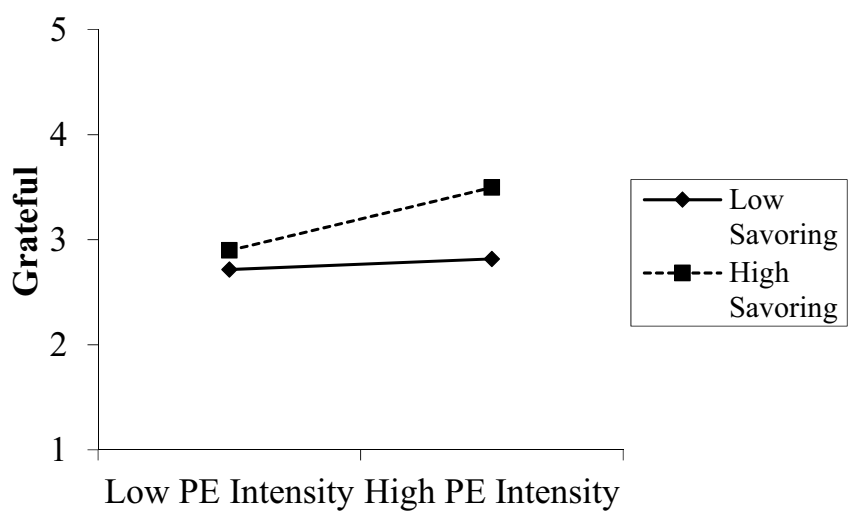

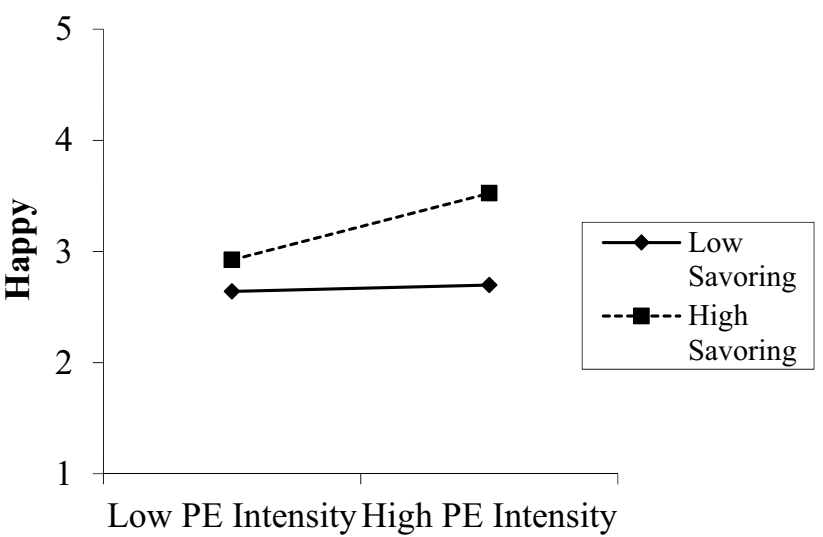

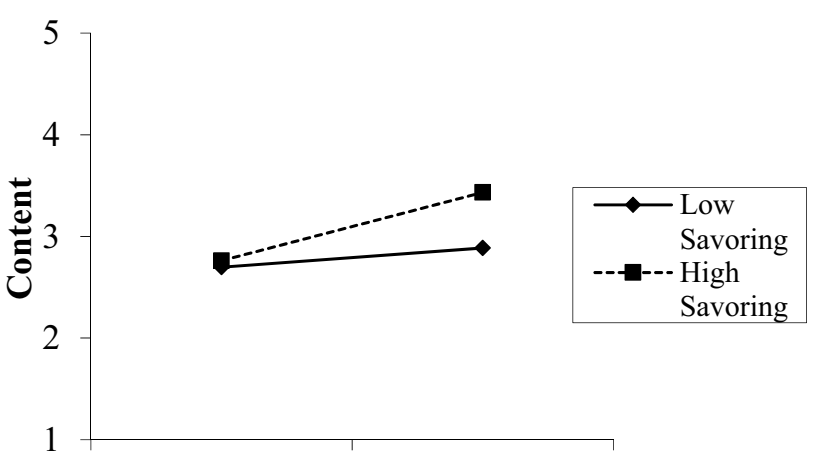

Low PE Intensity High PE Intensity

Fig. 1 Interactions between the intensity of positive daily events and savoring predicting daily positive emotions

Table 5 Multilevel regression models comparing cognitive reappraisal and savoring positive events as moderators of the association between negative event intensity and daily positive emotions

\begin{tabular}{|c|c|c|c|c|c|c|c|c|c|c|c|c|}
\hline \multirow{2}{*}{$\begin{array}{l}\text { Outcomes: } \\
\text { Predictors: }\end{array}$} & \multicolumn{3}{|l|}{ Happy } & \multicolumn{3}{|c|}{ Grateful } & \multicolumn{3}{|c|}{ Content } & \multicolumn{3}{|c|}{ Avg. Pos. Emo } \\
\hline & $b$ & $\beta$ & $t$ & $b$ & $\beta$ & $t$ & $b$ & $\beta$ & $t$ & $b$ & $\beta$ & $t$ \\
\hline Neg. Event Intensity & $-.21^{*}$ & $-.25^{*}$ & -7.29 & $-.15^{*}$ & $-.16^{*}$ & -4.83 & $-.34 *$ & $-.36^{*}$ & -10.93 & $-.24 *$ & $-.22 *$ & -9.33 \\
\hline Cognitive Reappraisal & $.18^{*}$ & $.14^{*}$ & 4.18 & $.26^{*}$ & $.19^{*}$ & $5.55^{*}$ & $.22^{*}$ & $.16^{*}$ & 4.84 & $.22 *$ & $.14^{*}$ & 5.91 \\
\hline $\begin{array}{l}\text { N.E. Intensity*Cognitive } \\
\text { Reappraisal }\end{array}$ & .07 & .05 & 1.44 & $.10 *$ & $.07 *$ & 1.99 & .03 & .02 & .65 & .06 & .03 & 1.64 \\
\hline Predictors & $b$ & $\beta$ & $t$ & $b$ & $\beta$ & $t$ & $b$ & $\beta$ & $t$ & $b$ & $\beta$ & $t$ \\
\hline Pos. Event Intensity & $.14^{*}$ & $.13^{*}$ & 3.64 & $.15^{*}$ & $.13^{*}$ & 3.62 & $.19^{*}$ & $.16^{*}$ & 4.48 & $.16^{*}$ & $.12 *$ & 4.81 \\
\hline Neg. Event Intensity & $-.17 *$ & $-.20 *$ & -6.13 & $-.11 *$ & $-.12 *$ & -3.62 & $-.32 *$ & $-.34 *$ & -10.04 & $-.21 *$ & $-.19 *$ & -8.11 \\
\hline Savoring & $.32 *$ & $.26^{*}$ & 7.02 & $.27^{*}$ & $.20 *$ & 5.22 & $.15^{*}$ & $.11^{*}$ & 2.88 & $.25^{*}$ & $.15^{*}$ & 6.10 \\
\hline N.E. Intensity*Savoring & -.02 & -.01 & -.39 & .06 & .04 & 1.41 & -.04 & -.03 & -.85 & .003 & .00 & .10 \\
\hline
\end{tabular}

Notes. ${ }^{*} p<.05$. Significant moderation effects are bolded. Positive Event Intensity was added as an additional covariate in models containing savoring. Avg. Pos. Emo. = Mean of Happy Grateful, and Content

When combining effective emotion regulation strategies into the same models (i.e. cognitive reappraisal, acceptance, and problem solving), only cognitive reappraisal and acceptance predicted unique variance in (more) positive and (less) negative daily emotion, respectively. Controlling for positive event intensity, savoring predicted more positive emotions and less sadness and annoyance but not anger. Savoring also moderated (strengthened) the association between positive event intensity and positive emotions. Finally, when comparing the moderating effects of cognitive reappraisal, 


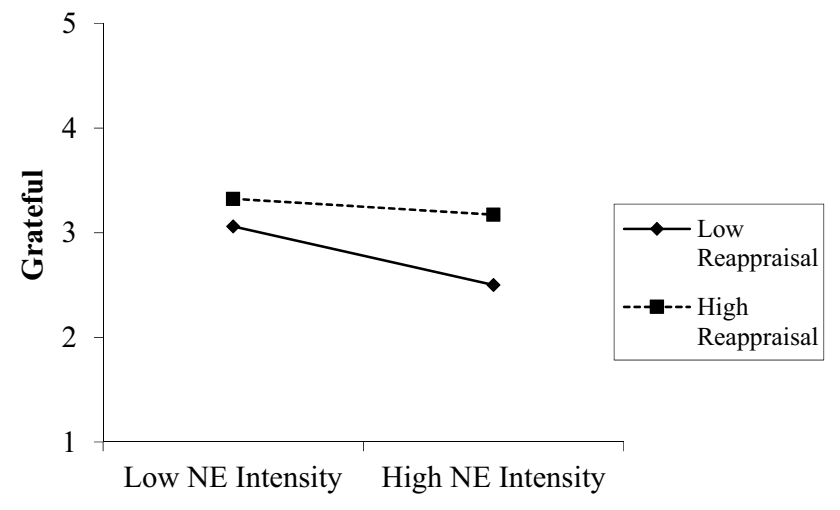

Fig. 2 Interaction between the intensity of daily negative events and reappraising negative events predicting daily gratitude

acceptance, and savoring on the association between daily negative events and emotions, accepting negative events and savoring positive events provided a greater buffer against negative emotional outcomes compared to cognitive reappraisal, which only buffered against the negative association between daily negative event intensity and gratitude.

The fact that cognitive reappraisal and acceptance emerged as significant, unique predictors of positive and negative emotions is consistent with a number of experience sampling and laboratory studies with non-athlete populations (Dunn et al. 2009; Eifert and Heffner 2003; Jamieson et al. 2013; Nezlek and Kuppens 2008; Troy et al. 2010) as well as cognitive-behavioral and mindfulness-based clinical interventions. These regulatory strategies are explored less frequently among college athletes in favor of studies focused on sport-specific coping and the effects of regulatory strategies on athletic performance (e.g. Hanin 2007;
Jones 2012; Laborde et al. 2014; Lane et al. 2011). Adopting a broader view, our study demonstrates the effectiveness of various emotion regulation strategies related to both positive and negative events in daily life, which could be sport or non-sport related. As awareness of and responsivity to athlete mental health concerns has finally begun to increase, it is important to understand emotion regulation within and beyond the sport context. Of course, stressful events from outside sport can impair sport performance without effective emotion regulation (e.g. Cosh and Tully 2015).

The fact that social support-seeking predicted more daily negative emotions may seem initially peculiar. Social support is often considered an adaptive form of emotion regulation, which promotes emotional and physical health (e.g. Demaray and Malecki 2002; Frasure-Smith et al. 2000; Turner 1981). However, some research suggests that social support-seeking in the form of co-rumination (i.e. discussing and revisiting problems, speculating about their cause, and focusing on negative feelings), is common among close friend groups (e.g. athletic teams) and associated with elevated depression and anxiety (Rose et al. 2007). It may be that social support-seeking took the form of co-rumination in our sample of young, predominantly female athletes and was thus associated with poor emotional outcomes.

It is important to differentiate social support seeking from the perception that one is obtaining the support they desire. Our measurement approach captured the act of seeking emotional and/or practical support from friends or family, not the perception of whether support was received or adequate. It may be that seeking social support was associated with increased negative emotions because athletes sought but never obtained adequate support. Research and theory suggest that seeking but not receiving social support is

Table 6 Multilevel regression models comparing acceptance and savoring positive events as moderators of the association between negative event intensity and daily negative emotions

\begin{tabular}{|c|c|c|c|c|c|c|c|c|c|c|c|c|}
\hline \multirow{2}{*}{$\begin{array}{l}\text { Outcomes: } \\
\text { Predictors }\end{array}$} & \multicolumn{3}{|l|}{ Sad } & \multicolumn{3}{|l|}{ Angry } & \multicolumn{3}{|c|}{ Annoyed } & \multicolumn{3}{|c|}{ Avg. Neg. Emo } \\
\hline & $b$ & $\beta$ & $t$ & $b$ & $\beta$ & $t$ & $b$ & $\beta$ & $t$ & $b$ & $\beta$ & $t$ \\
\hline Neg. Event Intensity & $.31^{*}$ & $.34^{*}$ & 10.10 & $.36^{*}$ & $.39 *$ & 11.58 & $.37 *$ & $.36^{*}$ & 10.82 & $.35^{*}$ & $.33 *$ & 13.53 \\
\hline Acceptance & $-.11 *$ & $-.11^{*}$ & -3.11 & $-.08^{*}$ & $-.08 *$ & -2.28 & -.05 & -.04 & -1.33 & $-.08^{*}$ & $-.07 *$ & -2.76 \\
\hline N.E. Intensity*Acceptance & $-.10 *$ & $-.09 *$ & -2.63 & $-.10 *$ & $-.09 *$ & -2.88 & -.05 & -.04 & -1.29 & $-.08 *$ & $-.06^{*}$ & -2.73 \\
\hline Predictors & $b$ & $\beta$ & $t$ & $b$ & $\beta$ & $t$ & $b$ & $\beta$ & $t$ & $b$ & $\beta$ & $t$ \\
\hline Pos. Event Intensity & $-.12 *$ & $-.11 *$ & -2.76 & -.08 & -.07 & -1.91 & $-.11^{*}$ & $-.09 *$ & -2.50 & $-.10^{*}$ & $-.08 *$ & -3.00 \\
\hline Neg. Event Intensity & $.31^{*}$ & $.34 *$ & 9.87 & $.35^{*}$ & $.38^{*}$ & 11.41 & $.36^{*}$ & $.35^{*}$ & 10.46 & $.34 *$ & $.32 *$ & 13.25 \\
\hline Savoring & -.08 & -.06 & -1.60 & -.04 & -.03 & -.89 & -.07 & -.05 & -1.31 & -.07 & -.05 & -1.59 \\
\hline N.E. Intensity*Savoring & -.06 & -.04 & -1.30 & $-.10 *$ & $-.09 *$ & -2.26 & $-.11 *$ & $-.07 *$ & -2.19 & $-.09 *$ & $-.05^{*}$ & -2.41 \\
\hline
\end{tabular}

Notes. $* p<.05$

Significant moderation effects are bolded

Positive Event Intensity was added as an additional covariate in models containing savoring

Avg. Neg. Emo. = Mean of sad, angry, and annoyed 

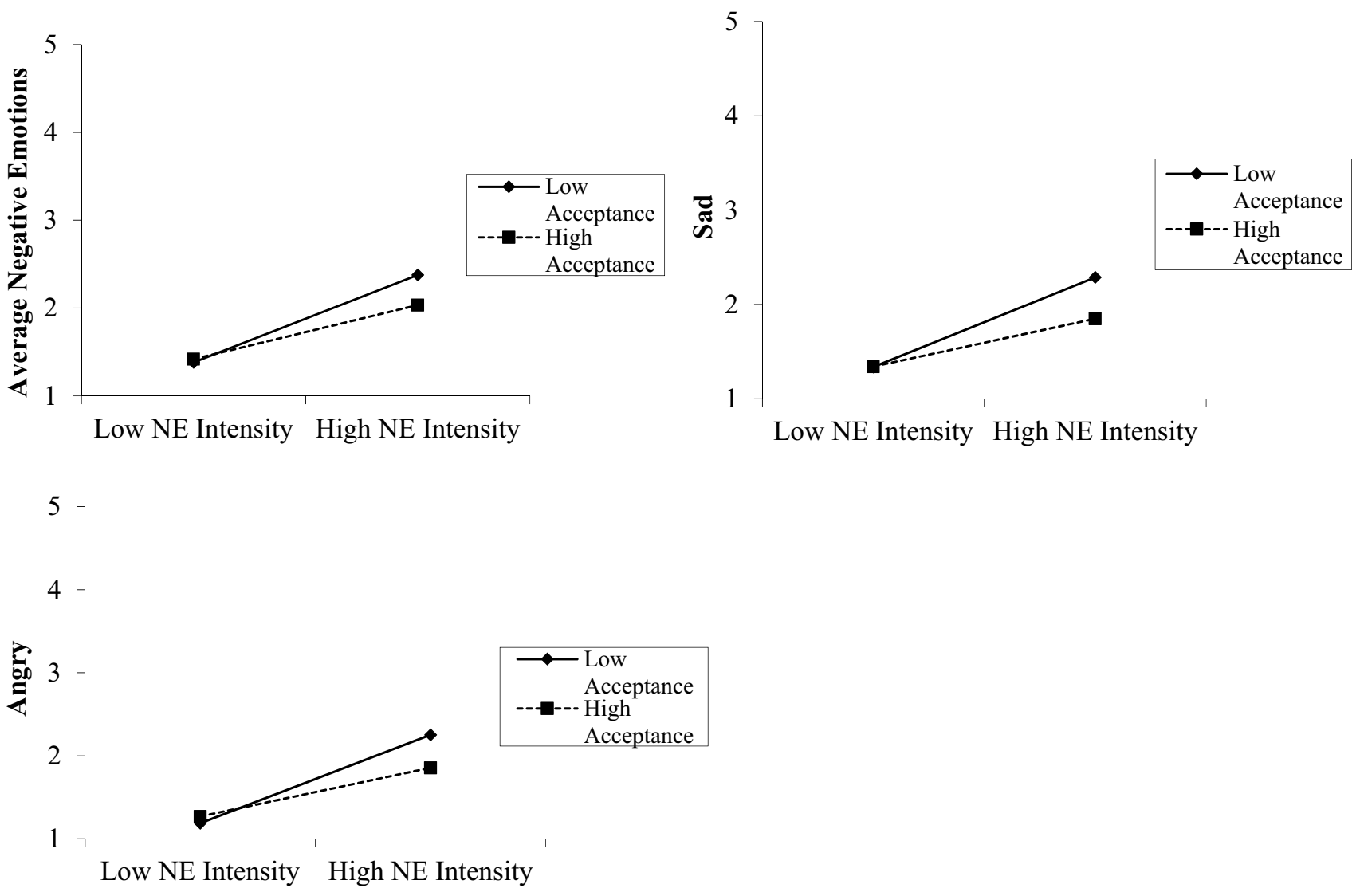

Fig. 3 Interactions between the intensity of daily negative events and accepting negative events predicting negative emotions

associated with a host of negative outcomes whether social support was sought in person (e.g. Cohen and Willis 1985) or via social media (Frison and Eggermont 2015). In fact, thwarted attempts at obtaining adequate support, along with perceiving that one is a burden on others (which may stem from these thwarted attempts), are well-established predictors of suicidal ideation among at-risk populations, including LGBTQ college students (e.g. Hill and Pettit 2012; Hill et al. 2017). Research should further explore how college athletes seek social support, particularly from their teammates and coaches, and which strategies for seeking and giving social support promote healthy responses to distress.

To our knowledge, our study is the first to explore savoring in the daily lives of athletes. When coaches, sport psychology consultants, and researchers focus solely on regulating negative emotions in response to negative events, another dimension of daily emotion and experience is ignored. Promising findings continue to emerge in the field of positive psychology, showing that interventions enhancing character strengths, gratitude, savoring, and compassion not only enhance positive emotions, but facilitate healthy responses to distress (Chaves et al. 2017; McMakin et al. 2011; Meyer et al. 2012; Sin and Lyubomirsky 2009; Smith and Hanni 2019). Our results add to this literature, suggesting that savoring, while unrelated to negative events, may be effective in regulating emotional responses to such events.

Mindfulness is widely considered an important trait for athlete performance and well-being (e.g. Aherne et al. 2011; Haase et al. 2015; Kaufman et al. 2009), but despite convincing evidence, savoring is not typically considered under the umbrella of mindfulness in athletic contexts. For example, a recent study suggests that team-based interventions with athletes that include gratitude and savoring components are effective in reducing sport burnout and enhancing sport satisfaction and well-being (Gabana et al. 2019). Research should explore whether more mindful athletes engage in more savoring, as they are adept at shifting their attention and encoding positive stimuli more deeply. Athletes who are less mindful may be less accepting of distress, become more entangled with it, and make greater attempts to change it (e.g. via cognitive reappraisal or other strategies).

The fact that savoring enhances athletes' emotional experience is not particularly surprising given findings from existing research with the general population (Bryant and Veroff 2007; Jose et al. 2012; Silton et al. 2020; Sytine et al. 2019; Quoidbach et al. 2015). Although, it is notable that savoring positive events buffered the effects of daily negative events on daily emotions - similar to accepting these 

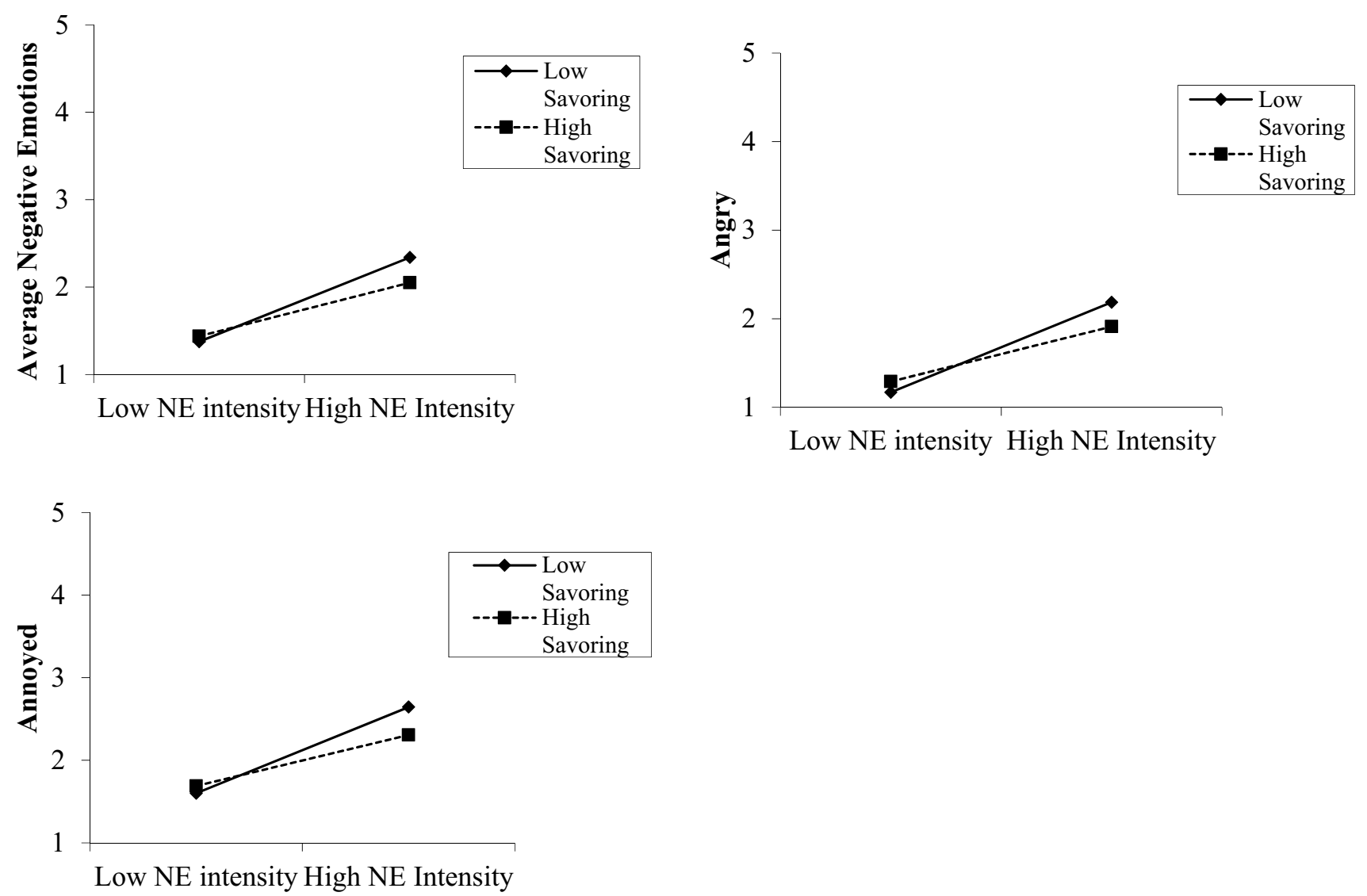

Fig. 4 Interactions between the intensity of daily negative events and savoring positive events predicting daily negative emotions, controlling for the intensity of positive events being savored

negative events and more so than reappraising them. Cognitive reappraisal is often touted as an optimal regulatory strategy (e.g. Gross and John 2003; Haga et al. 2009), but many studies fail to consider the contexts and individual differences that modulate its effectiveness. Recent research suggests that many individuals have difficulty using reappraisal effectively and that reappraisal can be ineffective in certain situations, such as when taking deliberate action would be more effective or when negative emotions are useful for achieving goals (e.g. Ford and Troy 2019; Troy et al. 2013).

Our findings add to this literature and other work on the benefits of acceptance and cognitive reappraisal (e.g. Vilardaga et al. 2013). Future research should not only explore reappraisal and acceptance among athletes individually, but also their co-occurrence. Emerging research suggests that some individuals may use multiple emotion regulation strategies at the same time, such as reappraisal and emotional suppression, with greater benefits than using only one (Sahdra et al. 2020). It would be valuable to know whether a certain combination of regulatory strategies used together enhance emotional outcomes for some athletes but not others.

\section{Limitations and Future Directions}

Our findings contribute new information to the study of emotion regulation among athletes, but several limitations must be considered. First, our analyses were correlational. While separate studies suggest reappraisal, acceptance, and savoring to play a causal role in reducing emotional distress, future experimental studies should compare the reappraisal, acceptance, and savoring interventions on emotional outcomes. Second, our findings are contingent upon our measurement approach. We used the four savoring items with the highest factor loadings from a widely used scale (Bryant and Veroff 2007), and these items predominantly captured the social aspects of savoring (e.g. "I talked to another person about how good I felt,") along with counting blessings ("I thought about what a lucky person I am that so many good things have happened to me"). Future studies should assess a wider range of savoring strategies at the daily level.

The generalizability of our findings is also limited by the scope of our daily cognitive reappraisal measure. We used two items from a daily coping scale published by Aldridge-Gerry et al. 2011, which captured "positive" 
cognitive reappraisal, specifically ("I reminded myself that things could be worse," "I tried to think about or notice only the good things in life") rather than general cognitive reappraisal (e.g. changing one's thinking about a situation to be more rational). The nature of our reappraisal measure may explain high between-person correlations with daily savoring $(r=0.71)$ since both measures capture a tendency to interpret events more positively. However, within-person correlations capturing the covariation of savoring and reappraisal each day across people were low (0.11). Still, while the cognitive behavioral therapy tradition emphasizes rational thinking, athletes and other populations may practice reappraisal differently, perhaps valuing positive over rational thinking. Using a succinct measure of daily emotion regulation was crucial for minimizing participant burnout, as we wished to measure a wide range of strategies each day. Future studies focused on reappraisal or a smaller range of strategies would benefit from adopting measures with more items and stronger content validity.

Third, with 67 athletes, our ability to conduct betweenperson analyses yielding stable results was limited. To harness all 836 daily observations, our hypotheses focused exclusively on within-person analyses. Despite barriers to recruiting college athletes for intensive longitudinal studies, researchers should strive to obtain larger samples to examine individual differences in within-person predictors of emotion regulation, including conscientiousness, negative emotionality, mindfulness, and self-compassion. It may be that individuals with higher trait levels of self-compassion are more likely to savor positive experiences due to beliefs that they are worthy. Given links between self-compassion and mindfulness, individuals with greater self-compassion may also derive greater benefits from savoring due to a tendency to live in the present.

Fourth, participants in our sample overwhelmingly identified as white $(91.1 \%)$. Experience sampling data suggest that individuals from racial, ethnic, and sexual minority groups use avoidant coping strategies more frequently on days when stigma-related stressors are reported (Hatzenbeuhler et al. 2009). Replications with more diverse samples may yield a wider range of reported positive and negative daily events and differences in terms of use of regulatory strategies and their impact on daily emotions.

Lastly, while we approached a range of men's and women's athletic teams, our final sample was overwhelmingly female (89\%). It is possible that the sex make-up of our sample significantly influenced our results and the generalizability of these results to the full spectrum of college athletes. Data suggest that women tend to use a wider range of emotion regulation strategies compared to men (NolenHoeksema and Aldao 2011; Thoits 1991). Women may also down-regulate negative emotions by upregulating positive emotions to a greater extent than men (e.g. McRae et al.
2008). Regarding savoring specifically, some evidence suggests that women may be more inclined to savor positive experiences than men (e.g. Bryant 2003; Kim and Bryant 2017) and are more open to positive psychological interventions to enhance savoring (e.g. Thompson et al. 2015). Taken together, this suggests that our findings related to savoring might not generalize to male athletes, but data are needed to support this claim. Researchers might consider exploring differences in savoring use and effectiveness among men. Researchers can also explore barriers and facilitators to implementing positive psychological interventions focused on savoring with men in athletic contexts specifically.

\section{Conclusions}

Despite these limitations, our study contributes valuable information to research on athlete emotion regulation and well-being. Our findings suggest that savoring positive events may be equally beneficial to accepting negative ones, and superior to cognitive reappraisal, in buffering against the negative emotional consequences of daily negative events. Coaches at the collegiate level and beyond often reference the importance of savoring wins, then immediately getting back to work. There is less emphasis on deliberately paying attention to and noticing positive emotions about productive practices, smaller individual improvements, downtime, and positive experiences with teammates. Our results underscore the potential importance of savoring daily positive events for mitigating emotional distress during the competitive season.

Our findings also have implications for the design of wellbeing and resilience focused interventions. While traditional clinical interventions, such as cognitive behavioral therapy, tend to focus on alleviating negative thoughts and emotions (e.g. with cognitive reappraisal), there has been a surge of interventions which aim instead to bolster psychological strengths and well-being (e.g. "Positive Psychotherapy;" Seligman et al. 2006). Positive psychotherapeutic interventions are primarily designed to upregulate positive states, traits, and experiences, but they may also reduce negative states and alleviate symptoms of serious mental health disorders, such as major depression and schizophrenia (e.g. Chaves et al. 2017; Meyer et al. 2012; Sin and Lyubomirsky 2009). Savoring-focused interventions also show promise for promoting healthy responses to stress and reducing depressed mood (Ho et al. 2014; Hurley and Kwon, 2012; Meyer et al. 2012; Smith and Hanni 2019). We hope this research program increases attention toward savoring as a way of managing the various stressors inherent to college athletics.

Acknowledgement This work was sponsored by a Graduate Student Research Grant from the National Collegiate Athletic Association. 
Portions of these findings were presented at the 2019 American Psychological Association Annual Convention in Chicago, IL and a research meeting at NCAA headquarters in Indianapolis, IN.

\section{Compliance with Ethical Standards}

Conflict of Interest James D. Doorley and Todd B. Kashdan have no conflicts of interest to disclose.

Informed Consent All procedures followed were in accordance with the ethical standards of the responsible committee on human experimentation (national and institutional). Informed consent was obtained from all individual subjects participating in the study. If any identifying information is contained in the paper the following statement is also necessary.

Animal Rights No animal studies were carried out by the authors for this article.

\section{References}

Aherne, C., Moran, A. P., \& Lonsdale, C. (2011). The effect of mindfulness training on athletes' flow: An initial investigation. The Sport Psychologist, 25(2), 177-189.

Aldridge-Gerry, A. A., Roesch, S. C., Villodas, F., McCabe, C., Leung, Q. K., \& Da Costa, M. (2011). Daily stress and alcohol consumption: modeling between-person and within-person ethnic variation in coping behavior. Journal of Studies on Alcohol and Drugs, 72(1), 125-134.

Bates, D., Sarkar, D., Bates, M. D., \& Matrix, L. (2007). The lme4 package. $R$ package version, 2(1), 74.

Bell, A. C., \& D'Zurilla, T. J. (2009). Problem-solving therapy for depression: A meta-analysis. Clinical Psychology Review, 29(4), 348-353.

Benson, L., English, T., Conroy, D. E., Pincus, A. L., Gerstorf, D., $\&$ Ram, N. (2019). Age differences in emotion regulation strategy use, variability, and flexibility: An experience sampling approach. Developmental Psychology, 55(9), 1951-1964.

Bolger, N., \& Laurenceau, J. P. (2013). Intensive longitudinal methods: An introduction to diary and experience sampling research. New York: Guilford Press.

Brennan, R. L. (1992). Generalizability theory. Educational Measurement: Issues and Practice, 11(4), 27-34.

Brockman, R., Ciarrochi, J., Parker, P., \& Kashdan, T. (2017). Emotion regulation strategies in daily life: mindfulness, cognitive reappraisal and emotion suppression. Cognitive Behaviour Therapy, 46(2), 91-113.

Broughton, E., \& Neyer, M. (2001). Advising and counseling student athletes. New Directions for Student Services, 93, 47-53.

Bryant, F. (2003). Savoring Beliefs Inventory (SBI): A scale for measuring beliefs about savouring. Journal of mental health, 12(2), 175-196.

Bryant, F. B., \& Veroff, J. (2007). Savoring: A new model of positive experience. Hove, UK: Psychology Press.

Carver, C. S. (1997). You want to measure coping but your protocol'too long: Consider the brief cope. International Journal of Behavioral Medicine, 4(1), 92-100.

Carver, C. S., Scheier, M. F., \& Weintraub, J. K. (1989). Assessing coping strategies: a theoretically based approach. Journal of Personality and Social Psychology, 56(2), 267-283.
Chaves, C., Lopez-Gomez, I., Hervas, G., \& Vazquez, C. (2017). A comparative study on the efficacy of a positive psychology intervention and a cognitive behavioral therapy for clinical depression. Cognitive Therapy and Research, 41(3), 417-433.

Cohen, S., \& Wills, T. A. (1985). Stress, social support, and the buffering hypothesis. Psychological bulletin, 98(2), 310-357.

Colombo, D., Fernández-Álvarez, J., Suso-Ribera, C., Cipresso, P., Valev, H., Leufkens, T., ... \& Botella, C. (2020). The need for change: Understanding emotion regulation antecedents and consequences using ecological momentary assessment. Emotion, 20(1), 30.

Connor-Smith, J. K., Compas, B. E., Wadsworth, M. E., Thomsen, A. H., \& Saltzman, H. (2000). Responses to stress in adolescence: Measurement of coping and involuntary stress responses. Journal of Consulting and Clinical Psychology, 68(6), 976.

Cosh, S., \& Tully, P. J. (2015). Stressors, coping, and support mechanisms for student athletes combining elite sport and tertiary education: Implications for practice. The Sport Psychologist, 29(2), 120-133.

Demaray, M. K., \& Malecki, C. K. (2002). The relationship between perceived social support and maladjustment for students at risk. Psychology in the Schools, 39(3), 305-316.

Dickens, Y. L., Van Raalte, J., \& Hurlburt, R. T. (2018). On investigating self-talk: A descriptive experience sampling study of inner experience during golf performance. The Sport Psychologist, 32(1), 66-73.

Dunn, B. D., Billotti, D., Murphy, V., \& Dalgleish, T. (2009). The consequences of effortful emotion regulation when processing distressing material: A comparison of suppression and acceptance. Behaviour Research and Therapy, 47(9), 761-773.

Eifert, G. H., \& Heffner, M. (2003). The effects of acceptance versus control contexts on avoidance of panic-related symptoms. Journal of Behavior Therapy and Experimental Psychiatry, 34(3-4), 293-312.

Ellison, W. D. (2020). An initial study of practicing psychologists' views of the utility of ecological momentary assessment for difficult psychotherapy cases. Administration and Policy in Mental Health and Mental Health Services Research, 1-11.

Evans, B. PACO Personal Analytics Companion. 2017.

Ford, B. Q., \& Troy, A. S. (2019). Reappraisal reconsidered: A closer look at the costs of an acclaimed emotion-regulation strategy. Current Directions in Psychological Science, 28(2), 195-203.

Frasure-Smith, N., Lespérance, F., Gravel, G., Masson, A., Juneau, M., Talajic, M., \& Bourassa, M. G. (2000). Social support, depression, and mortality during the first year after myocardial infarction. Circulation, 101(16), 1919-1924.

Frison, E., \& Eggermont, S. (2015). The impact of daily stress on adolescents' depressed mood: The role of social support seeking through Facebook. Computers in Human Behavior, 44, 315-325.

Gabana, N. T., Steinfeldt, J., Wong, Y. J., Chung, Y. B., \& Svetina, D. (2019). Attitude of gratitude: Exploring the implementation of a gratitude intervention with college athletes. Journal of Applied Sport Psychology, 31(3), 273-284.

Gaudreau, P., \& Blondin, J. P. (2004a). Different athletes cope differently during a sport competition: A cluster analysis of coping. Personality and Individual Differences, 36(8), 1865-1877.

Gaudreau, P., \& Blondin, J. P. (2004b). Differential Associations of Dispositional Optimism and Pessimism With Coping, Goal Attainment, and Emotional Adjustment During Sport Competition. International Journal of Stress Management, 11(3), 245-269.

Gerber, A. J., Posner, J., Gorman, D., Colibazzi, T., Yu, S., Wang, Z., ... \& Peterson, B. S. (2008). An affective circumplex model of neural systems subserving valence, arousal, and cognitive overlay during the appraisal of emotional faces. Neuropsychologia, 46(8), 2129-2139. 
Gratz, K. L., \& Tull, M. T. (2010). Emotion regulation as a mechanism of change in acceptance-and mindfulness-based treatments. In K. L. Gratz (Ed.), Assessing mindfulness and acceptance processes in clients: Illuminating the theory and practice of change (pp. 107-133). Oakland, USA: Context Press.

Gross, J. J., \& John, O. P. (2003). Individual Differences in Two Emotion Regulation Processes: Implications for Affect, Relationships, and Well-Being. Journal of Personality and Social Psychology, 85(2), 348-362.

Gruber, J., Kogan, A., Mennin, D., \& Murray, G. (2013). Real-world emotion? An experience-sampling approach to emotion experience and regulation in bipolar I disorder. Journal of Abnormal Psychology, 122(4), 971-983.

Haase, L., May, A. C., Falahpour, M., Isakovic, S., Simmons, A. N., Hickman, S. D., \& Paulus, M. P. (2015). A pilot study investigating changes in neural processing after mindfulness training in elite athletes. Frontiers in Behavioral Neuroscience, 9, 1-12.

Haga, S. M., Kraft, P., \& Corby, E. K. (2009). Emotion regulation: Antecedents and well-being outcomes of cognitive reappraisal and expressive suppression in cross-cultural samples. Journal of Happiness Studies, 10(3), 271-291.

Hanin, Y. L. (2007). Emotions and athletic performance: Individual zones of optimal functioning model. In D. Smith \& M. Bar-Eli (Eds.), Human kinetics. Washington: American Psychological Association.

Hatzenbuehler, M. L., Nolen-Hoeksema, S., \& Dovidio, J. (2009). How does stigma "get under the skin"? The mediating role of emotion regulation. Psychological Science, 20(10), 1282-1289.

Hill, R. M., \& Pettit, J. W. (2012). Suicidal ideation and sexual orientation in college students: The roles of perceived burdensomeness, thwarted belongingness, and perceived rejection due to sexual orientation. Suicide and Life-Threatening Behavior, 42(5), 567-579.

Hill, R. M., Rooney, E. E., Mooney, M. A., \& Kaplow, J. B. (2017). Links between social support, thwarted belongingness, and suicide ideation among lesbian, gay, and bisexual college students. Journal of Family Strengths, 17(2), 1-25.

Ho, H. C., Yeung, D. Y., \& Kwok, S. Y. (2014). Development and evaluation of the positive psychology intervention for older adults. The Journal of Positive Psychology, 9(3), 187-197.

Hofmann, S. G., Heering, S., Sawyer, A. T., \& Asnaani, A. (2009). How to handle anxiety: The effects of reappraisal, acceptance, and suppression strategies on anxious arousal. Behaviour Research and Therapy, 47(5), 389-394.

Hurley, D. B., \& Kwon, P. (2012). Results of a study to increase savoring the moment: Differential impact on positive and negative outcomes. Journal of Happiness Studies, 13(4), 579-588.

Hurley, D. B., \& Kwon, P. (2013). Savoring helps most when you have little: Interaction between savoring the moment and uplifts on positive affect and satisfaction with life. Journal of Happiness Studies, 14(4), 1261-1271.

Jamieson, J. P., Mendes, W. B., \& Nock, M. K. (2013). Improving acute stress responses: The power of reappraisal. Current Directions in Psychological Science, 221, 51-56.

Jones, M. V. (2012). Emotion regulation and performance. In M. V. Jones (Ed.), The Oxford handbook of sport and performance psychology (pp. 154-172). Oxford: Oxford University Press.

Jose, P. E., Lim, B. T., \& Bryant, F. B. (2012). Does savoring increase happiness? A daily diary study. The Journal of Positive Psychology, 7(3), 176-187.

Kashdan, T. B., Barrios, V., Forsyth, J. P., \& Steger, M. F. (2006). Experiential avoidance as a generalized psychological vulnerability: Comparisons with coping and emotion regulation strategies. Behaviour Research and Therapy, 44(9), 1301-1320.

Kaufman, K. A., Glass, C. R., \& Arnkoff, D. B. (2009). Evaluation of Mindful Sport Performance Enhancement (MSPE): A new approach to promote flow in athletes. Journal of Clinical Sport Psychology, 3(4), 334-356.

Kim, S., \& Bryant, F. B. (2017). The influence of gender and cultural values on savoring in Korean undergraduates. International Journal of Wellbeing, 7(2), 43-63.

Kimball, A., \& Freysinger, V. J. (2003). Leisure, stress, and coping: The sport participation of collegiate student-athletes. Leisure Sciences, 25(2-3), 115-141.

Kuba, K., \& Scheibe, S. (2017). Let it be and keep on going! Acceptance and daily occupational well-being in relation to negative work events. Journal of Occupational Health Psychology, 22(1), $59-70$.

Laborde, S., Lautenbach, F., Allen, M. S., Herbert, C., \& Achtzehn, S. (2014). The role of trait emotional intelligence in emotion regulation and performance under pressure. Personality and Individual Differences, 57, 43-47.

Lane, A. M., Beedie, C. J., Devonport, T. J., \& Stanley, D. M. (2011). Instrumental emotion regulation in sport: relationships between beliefs about emotion and emotion regulation strategies used by athletes. Scandinavian Journal of Medicine \& Science in Sports, 21(6), e445-e451.

Lazarus, R. S. (2006). Stress and emotion: A new synthesis. Springer Publishing Company.

Lazarus, R. S., \& Folkman, S. (1984). Stress, appraisal, and coping. Springer publishing company.

Lorah, J. (2018). Effect size measures for multilevel models: Definition, interpretation, and TIMSS example. Large-Scale Assessments in Education, 6(1), 8-19.

Loudon, D. L., Stevens, R. E., Yow, D. A., Humphrey, J. H., \& Bowden, W. W. (2013). Stress in college athletics: Causes, consequences, coping. Milton Park: Routledge.

Ludwig, L., Mehl, S., Krkovic, K., \& Lincoln, T. M. (2020). Effectiveness of emotion regulation in daily life in individuals with psychosis and nonclinical controls-An experience-sampling study. Journal of Abnormal Psychology. https://doi.org/10.1037/abn00 00505.

Machell, K. A., Goodman, F. R., \& Kashdan, T. B. (2015). Experiential avoidance and well-being: A daily diary analysis. Cognition and Emotion, 29(2), 351-359.

Marroquín, B. (2011). Interpersonal emotion regulation as a mechanism of social support in depression. Clinical Psychology Review, 31(8), 1276-1290.

Martinent, G., Ledos, S., Ferrand, C., Campo, M., \& Nicolas, M. (2015). Athletes' regulation of emotions experienced during competition: A naturalistic video-assisted study. Sport, Exercise, and Performance Psychology, 4(3), 188-207.

McMakin, D. L., Siegle, G. J., \& Shirk, S. R. (2011). Positive Affect Stimulation and Sustainment (PASS) module for depressed mood: A preliminary investigation of treatment-related effects. Cognitive Therapy and Research, 35(3), 217-226.

McRae, K., Ciesielski, B., \& Gross, J. J. (2012). Unpacking cognitive reappraisal: goals, tactics, and outcomes. Emotion, 12(2), 250-255.

McRae, K., Ochsner, K. N., Mauss, I. B., Gabrieli, J. J., \& Gross, J. J. (2008). Gender differences in emotion regulation: An fMRI study of cognitive reappraisal. Group Processes \& Intergroup Relations, 11(2), 143-162.

Meyer, B. (2001). Coping with severe mental illness: Relations of the Brief COPE with symptoms, functioning, and well-being. Journal of Psychopathology and Behavioral Assessment, 23(4), 265-277.

Meyer, P. S., Johnson, D. P., Parks, A., Iwanski, C., \& Penn, D. L. (2012). Positive living: A pilot study of group positive psychotherapy for people with schizophrenia. The Journal of Positive Psychology, 7(3), 239-248. 
Min, J. A., Yu, J. J., Lee, C. U., \& Chae, J. H. (2013). Cognitive emotion regulation strategies contributing to resilience in patients with depression and/or anxiety disorders. Comprehensive Psychiatry, 54(8), 1190-1197.

Moore, S. A., Zoellner, L. A., \& Mollenholt, N. (2008). Are expressive suppression and cognitive reappraisal associated with stressrelated symptoms? Behaviour Research and Therapy, 46(9), 993-1000.

Neubauer, A. B., Scott, S. B., Sliwinski, M. J., \& Smyth, J. M. (2019). How was your day? Convergence of aggregated momentary and retrospective end-of-day affect ratings across the adult life span. Journal of Personality and Social Psychology. https://doi. org/10.1037/pspp0000248.

Nezlek, J. B. (2011). Multilevel modeling for social and personality psychology. California: SAGE Publications Ltd.

Nezlek, J. B. (2012). Multilevel modeling analyses of diary-style data. In J. B. Nezlek (Ed.), Handbook of Research Methods for Studying Daily Life (pp. 357-383). New York: Guilford Press.

Nezlek, J. B., \& Kuppens, P. (2008). Regulating positive and negative emotions in daily life. Journal of Personality, 76(3), 561-580.

Nolen-Hoeksema, S., \& Aldao, A. (2011). Gender and age differences in emotion regulation strategies and their relationship to depressive symptoms. Personality and Individual Differences, 51(6), 704-708.

Olatunji, B. O., Cisler, J. M., \& Deacon, B. J. (2010). Efficacy of cognitive behavioral therapy for anxiety disorders: A review of metaanalytic findings. Psychiatric Clinics, 33(3), 557-577.

Ollendick, T. H., Langley, A. K., Jones, R. T., \& Kephart, C. (2001). Fear in children and adolescents: Relations with negative life events, attributional style, and avoidant coping. Journal of Child Psychology and Psychiatry, 42(8), 1029-1034.

Poczwardowski, A., \& Conroy, D. E. (2002). Coping responses to failure and success among elite athletes and performing artists. Journal of Applied Sport Psychology, 14(4), 313-329.

Quoidbach, J., Mikolajczak, M., \& Gross, J. J. (2015). Positive interventions: An emotion regulation perspective. Psychological Bulletin, 141(3), 655-693.

Riley, K. E., Tigershtrom, A., Park, C. L., \& Lauranceau, J. P. (2020). Predictors of health behaviors during a college national championship sports event: A daily diary study. Journal of American College Health. https://doi.org/10.1080/07448481.2020.17191 10.

Roesch, S. C., Aldridge, A. A., Stocking, S. N., Villodas, F., Leung, Q., Bartley, C. E., \& Black, L. J. (2010). Multilevel factor analysis and structural equation modeling of daily diary coping data: Modeling trait and state variation. Multivariate Behavioral Research, 45(5), 767-789.

Rose, A. J., Carlson, W., \& Waller, E. M. (2007). Prospective associations of co-rumination with friendship and emotional adjustment: Considering the socioemotional trade-offs of co-rumination. Developmental Psychology, 43(4), 1019-1031.

Sahdra, B. K., Brockman, R., Hayes, S. C., Hofmann, S. G., Kashdan, T. B., \& Ciarrochi, J. (2020). Individual differences in the co-use of reappraisal and emotion suppression in daily life: Implications for daily positive and negative affect. Reappraisal \& Suppressionin Daily Life. https://doi.org/10.31234/osf.io/w4u7r.

Scollon, C. N., Prieto, C. K., \& Diener, E. (2009). Experience sampling: promises and pitfalls, strength and weaknesses. In C. N. Scollon (Ed.), Assessing well-being (pp. 157-180). New York: Springer.

Seligman, M. E., Rashid, T., \& Parks, A. C. (2006). Positive psychotherapy. American Psychologist, 61(8), 774-788.

Settles, I. H., Sellers, R. M., \& Damas, A., Jr. (2002). One role or two?: The function of psychological separation in role conflict. Journal of Applied Psychology, 87(3), 574-582.
Shapiro, J. L., Brewer, B. W., Cornelius, A. E., \& Van Raalte, J. L. (2017). Patterns of emotional response to ACL reconstruction surgery. Journal of Clinical Sport Psychology, 11(3), 169-180.

Shorey, R. C., Stuart, G. L., Moore, T. M., \& McNulty, J. K. (2014). The temporal relationship between alcohol, marijuana, angry affect, and dating violence perpetration: A daily diary study with female college students. Psychology of Addictive Behaviors, 28(2), 516-523.

Shrout, P. E., \& Lane, S. P. (2012). Psychometrics. In M. R. Mehl \& T. S. Conner (Eds.), Handbook of Research Methods for Studying Daily Life (pp. 302-320). New York: The Guilford Press.

Silton, R. L., Kahrilas, I. J., Skymba, H. V., Smith, J., Bryant, F. B., \& Heller, W. (2020). Regulating positive emotions: Implications for promoting well-being in individuals with depression. Emotion, 20(1), 93-97.

Sin, N. L., \& Lyubomirsky, S. (2009). Enhancing well-being and alleviating depressive symptoms with positive psychology interventions: A practice-friendly meta-analysis. Journal of Clinical Psychology, 65(5), 467-487.

Smith, B. W., Dalen, J., Wiggins, K., Tooley, E., Christopher, P., \& Bernard, J. (2008). The brief resilience scale: assessing the ability to bounce back. International Journal of Behavioral Medicine, 15(3), 194-200.

Smith, J. L., \& Hanni, A. A. (2019). Effects of a savoring intervention on resilience and well-being of older adults. Journal of Applied Gerontology, 38, 137-152.

Sytine, A. I., Britt, T. W., Sawhney, G., Wilson, C. A., \& Keith, M. (2019). Savoring as a moderator of the daily demands and psychological capital relationship: A daily diary study. The Journal of Positive Psychology, 14(5), 641-648.

Tamminen, K. A., Page-Gould, E., Schellenberg, B., Palmateer, T., Thai, S., Sabiston, C. M., \& Crocker, P. R. (2019). A daily diary study of interpersonal emotion regulation, the social environment, and team performance among university athletes. Psychology of Sport and Exercise, 45, 101566.

Thoits, P. A. (1991). Gender differences in coping with emotional distress. In P. A. Thoits (Ed.), The social context of coping (pp. 107-138). New York: Springer.

Thompson, R. B., Peura, C., \& Gayton, W. F. (2015). Gender differences in the person-activity fit for positive psychology interventions. The Journal of Positive Psychology, 10(2), 179-183.

Troy, A. S., \& Mauss, I. B. (2011). Resilience in the face of stress: Emotion regulation as a protective factor. Resilience and mental health: Challenges across the lifespan, 1(2), 30-44.

Troy, A. S., Shallcross, A. J., \& Mauss, I. B. (2013). A person-bysituation approach to emotion regulation: Cognitive reappraisal can either help or hurt, depending on the context. Psychological Science, 24(12), 2505-2514.

Troy, A. S., Wilhelm, F. H., Shallcross, A. J., \& Mauss, I. B. (2010). Seeing the silver lining: Cognitive reappraisal ability moderates the relationship between stress and depressive symptoms. Emotion, 10(6), 783-795.

Tugade, M. M., \& Fredrickson, B. L. (2007). Regulation of positive emotions: Emotion regulation strategies that promote resilience. Journal of Happiness Studies, 8(3), 311-333.

Turner, R. J. (1981). Social support as a contingency in psychological well-being. Journal of Health and Social Behavior, 22, 357-367.

Uphill, M. A., Lane, A. M., \& Jones, M. V. (2012). Emotion Regulation Questionnaire for use with athletes. Psychology of Sport and Exercise, 13(6), 761-770.

Van Raalte, J. L., Vincent, A., \& Dickens, Y. L. (2019). Dialogical consciousness and descriptive experience sampling: Implications for the study of intrapersonal communication in sport. Frontiers in Psychology, 10, 653-657.

Vilardaga, R., Hayes, S. C., Atkins, D. C., Bresee, C., \& Kambiz, A. (2013). Comparing experiential acceptance and cognitive 
reappraisal as predictors of functional outcome in individuals with serious mental illness. Behaviour Research and Therapy, 51(8), 425-433.

Visser, K. F., Esfahlani, F. Z., Sayama, H., \& Strauss, G. P. (2018). An ecological momentary assessment evaluation of emotion regulation abnormalities in schizophrenia. Psychological Medicine, 48(14), 2337-2345.

Watson, D., \& Clark, L. A. (1999). The PANAS-X: Manual for the positive and negative affect schedule-expanded form.

Watson, J. C., \& Kissinger, D. B. (2007). Athletic participation and wellness: Implications for counseling college student-athletes. Journal of College Counseling, 10(2), 153-162.
Wolgast, M., Lundh, L. G., \& Viborg, G. (2011). Cognitive reappraisal and acceptance: An experimental comparison of two emotion regulation strategies. Behaviour research and therapy, 49(12), $858-866$

Publisher's Note Springer Nature remains neutral with regard to jurisdictional claims in published maps and institutional affiliations. 